\title{
Internet Addiction: The Emergence of a New Clinical Disorder
}

\author{
*MA Habib
}

\section{Introduction}

Recent reports indicated that some internet users were being addicted to the internet in much the same way those others become addicted to drugs, alcohol or gambling, which results in academic failure, reduced work performance and even marital discord and separation. Beginning in the late 1980s, the first case studies were reported which led to early definitions of the problem adapting diagnostic criteria from other addictions. A particularly comprehensive definition that does not adhere to diagnostic criteria was offered by Beard and Wolf. "Overuse of the Internet leading to impairment of an individual's mental, emotional and psychological states as well as their scholastic, occupational and social interactions."

Currently there are two major means of identifying internet addiction. One drafted by Young and other by Griffiths. Young argues that anyone possessing five or more of a set of eight symptoms suffers from internet addiction with the symptoms including 1. Preoccupation with thinking about the internet and anticipating the next session. 2. Increasing amount of time needed to gain same level of satisfaction; 3. Unsuccesful efforts to control, cut back or stop; 4. Restless, moody, irritable and depressed mood when attempting to cut down or stop; 5. Staying on longer than intended; 6. Jeopardizing the loss of significant relationship, job, school or carrier opportunities; 7. Lying to family members and others to conceal involvement; and 8 . Using the internet to escape from problems or relieve dysphonic mood including feeling of helplessness, anxiety, and depression.

Griffiths on the other hand, sees five areas that combine to define Internet addiction 1. Salience, when Internet becomes the most important thing in the life to the extent that the adolescent neglect basic human needs; 2. Mood modification, in which the adolescent Internet addict uses Internet to escape a bad mood or numb oneself and get irritated if not allowed to be online; 3. Tolarence, in which it takes the addict more and more time on the Internet to achieve same positive feelings; 5 . Relapse, in which any attempts to control one's use lead instead to overuse.

Internet addiction shows prevalence among adolescents ranging from $2-15.3 \%$ with boys showing more prevalence than girls and Asian countries more than western. Many studies revealed the negative impact of Internet addiction such as school burnout, increased risk taking attitude, increased depressive disorder, symptoms of ADHD, and feelings of loss of control, anger, social withdrawal, and familial conflicts leading to mental health problems.

In Bangladesh extensive studies are done yet to reveal prevalence, and negative impacts. But professional communications exposed the fact that the rate of Internet addiction is increasing.

Video gaming addiction has been studied the most among the subareas of Internet addiction. Also much work has been done examining social media addiction, particularly apropos as social media use accounts for more Internet time than any other activities. Researchers found that more social media usage predicted more Internet addiction which in turn predicted more psychological distress specially among adolescents.

The bottom line is that internet addiction is a complex phenomenon which impacts a growing pool of adolescents, our future generation. For better tomorrow we must act now. We should start extensive work to find out the prevalence, better treatment methods and measures for prevention.

Prof. Dr. Mohammad Ahsanul Habib, Professor of Psychiatry, Anwer Khan Modern Medical College

e-mail: rubelsaria@gmail.com

*Corresponding Author

AKMMC J 2019; 10(2) : 103-104 


\section{References}

1. Vondrackova P, Smahel D. Internet addiction In Wiley handbook of psychology, technology and society. Wiley-blackwell; 2015.p.469-85

2. Young KS. Internet addiction: the emergence of a new clinical disorder. Cyberpsychol. Behave. 1998; 1(3): 237-44.

3. Beard KW. Wolf EM. Modification in the proposed diagnostic criteria for internet addiction. Cyberpsychol Behav. 2001; 4(3): 377-83.

4. Griffiths M. Does internet and computer "addiction" exists? Some case study evidence. Cyberpsychol Behav. 2000; 3(2): 211-8

5. Salmela-Aro K, Upadyaya K, Hakkarainen K, et al. The dark side of internet use: two longitudinal studies of excessive internet use, depressive symptoms, school burnout and engagement among Finnish early and late adolescents. J Youth Adolesc. 2016; 2: 1-5
6. Oktan V. An investigation of problematic internet use among adolescents in term of self-injuries and risk taking behavior. Child Youth Serv. Rev. 2015; 52: 63-7.

7. Jorgenson AG. Hsiao RC. Yen CF. Internet addiction and other behavioral addiction. Child Adolesc. Psychiatr Clin Am. 2016; 25(3): 509-20.

8. Cerniglia L. Zoratto F. Cimino S. et al. Internet addiction in adolescents, neurobiological, psychological and clinical issue. Neurosci Biobehav Rev 2017; 78(Pt A): 74-84.

9. Mullar KW, Dreier M, Beutal ME, et al. A hidden type of internet addiction? Intense and addictive use of social networking sites in adolescents. Compt Hum Behav. 2014; 55: 172-7. 